\title{
O DESPERTAR PARA UMA EDUCAÇÃO AMBIENTAL: A REALIDADE DA ESCOLA MUNICIPAL BAIXA DA FARTURA NO ASSENTAMENTO AMARALINA
}

\author{
Laily Soura Benedictis ${ }^{1}$
}

\begin{abstract}
RESUMO
No presente artigo, relata-se alguns resultados da pesquisa monográfica de conclusão do curso de Licenciatura Plena em Geografia, realizada entre 2009 e 2010. Esse estudo objetivou analisar a prática da Educação Ambiental desenvolvida pela Escola Municipal Baixa da Fartura, localizada no Assentamento Amaralina, em Vitória da Conquista/BA. Buscou-se ainda, identificar práticas pedagógicas no cotidiano escolar. Empiricamente, foi possível verificar que o corpo docente direciona a discussão ambiental sob a perspectiva do descarte do lixo e a higiene pessoal. Ficou evidente que há a necessidade de planejamento referente à prática de ações que contemplem a Educação Ambiental na Instituição.
\end{abstract}

Palavras-chave: Cotidiano escolar. Discussão ambiental. Práticas pedagógicas.

\footnotetext{
${ }^{1}$ Graduada em Licenciatura Plena em Geografia pela Universidade Estadual do Sudoeste da Bahia (UESB). Especializada em Geografia pela Universidade Estadual do Sudoeste da Bahia (UESB). Membro do grupo de pesquisa do CNPq: Educação, Políticas Públicas, Meio Ambiente e Representações; E-mail: laybenedictis@hotmail.com. Trabalho orientado pela Prof ${ }^{a}$ Mestre Nêreida $\mathrm{M}^{\mathrm{a}}$ Mafra Santos Benedictis do Departamento de Geografia da UESB; coordenadora da linha de pesquisa Educação, Políticas Públicas Meio Ambiente e Representações. E-mail: nereidamafrabenedictis@gtmail.com.
}

\begin{tabular}{l|l|l|l|l}
\hline Revista Extensão \& Cidadania & Vitória da Conquista & v. 1, n. 2 & p. 41-51 & jul/dez. 2013 \\
\hline
\end{tabular}




\title{
THE AWAKENING FOR ENVIRONMENTAL EDUCATION: THE REALITY OF THE ESCOLA MUNICIPAL BAIXA DA FARTURA IN LAYING AMARALINA WEALTH
}

\begin{abstract}
In this paper, we report some results of the research monographic course completion Full Degree in Geography, conducted between 2009 and 2010. This study aimed to analyze the practice of environmental education developed by the Escola Municipal Baixa da Fartura, located in the Assentamento Amaralina in Vitória da Conquista/BA. We sought to further identify pedagogical practices in school life. Empirically, we found that faculty directs the discussion from the perspective of environmental waste disposal and personal hygiene. It was evident that there is a need for planning related to the practice of actions that include Environmental Education Institution.
\end{abstract}

Keywords: Everyday school. Environmental discussion. Pedagogical practices.

\section{Introdução}

Esse artigo tem como objetivo relatar alguns resultados da monografia de conclusão do curso de Licenciatura Plena em Geografia, a qual privilegiou a análise da prática da Educação Ambiental desenvolvida pela Escola Municipal Baixa da Fartura, localizada no Assentamento Amaralina, no município de Vitória da Conquista/BA.

O presente trabalho aborda um recorte da contextualização teórica discutida na pesquisa monográfica, com destaque para um breve histórico da Educação Ambiental no Brasil. Descreve também, a análise empírica da escola citada, citando na íntegra as colocações dos profissionais entrevistados.

A pesquisa foi direcionada por meio da análise do Projeto Político Pedagógico (PPP, 2006) da instituição Escola Municipal Baixa da Fartura, que destaca os princípios filosóficos, teóricos e pedagógicos que fundamentam a educação do Movimento dos Trabalhadores Rurais Sem Terra (MST).

Em seguida, realizou-se a coleta de dados, em campo, para obtenção de dados quantitativos e qualitativos. Para tanto, utilizou-se instrumento de pesquisa empírica, tal como: questionários, entrevistas diretas e individuais com a coordenação e corpo docente da referida Escola. 
Delineiam-se aqui, os alicerces da Educação Ambiental (EA), os quais foram construídos em Tibilisi, cujas determinações foram aperfeiçoadas nos grandes encontros internacionais subsequentes, como a Conferência sobre Meio Ambiente e Desenvolvimento, realizada no Rio de Janeiro, em junho de 1992, que contou com a participação de 179 países. Essa conferência ficou conhecida como RIO-92 e representou o mais importante encontro internacional já realizado, como afirma Crespo (2003, p. 63):

A importância desse ato de qualidade que a RIO-92 produziu diretamente sobre o movimento ambientalista no Brasil e sobre a consciência da população de um modo geral foi descrito em todas as suas cores, em coros, por militantes ambientalistas e os outros setores [...] O Brasil em termos ambientais, nunca mais foi o mesmo depois da Rio-92.

A Agenda 21 foi o produto da Conferência das Nações Unidas sobre meio ambiente e desenvolvimento sustentável e é apontada como um dos mais importantes documentos em busca de uma harmonização de desenvolvimento econômico para a proteção ambiental. Portanto, não é um documento de governos, mas um produto de consenso entre os diversos setores da sociedade.

Assim, "A Agenda 21 menciona uma nova discussão teórica sobre as relações entre economia, crescimento econômico e o próprio conceito de consumo tal qual tem sido utilizado no processo de tomada de decisão dos governos." (FELDMAN, 2003, p. 154). Desse modo, torna-se um plano de Ação para a humanidade, o qual coloca o desenvolvimento sustentável como uma estratégia de sobrevivência. Sobre isso, Novaes (2003) aponta,

De fato, o documento tratava de praticamente todas as grandes questões, dos padrões e consumo à luta para erradicar a pobreza no mundo e às políticas de desenvolvimento sustentável [...] Tentava também criar mecanismos financeiros para viabilizar esses caminhos (NOVAES, 2003, p. 324). 
A Constituição brasileira de 1988, em Art. 255, no Capítulo VI, inciso VI, destaca a necessidade de promover a EA em todos os níveis de ensino, buscando a conscientização pública para a preservação do meio ambiente. Para isso, regulamentou-se preceitos constitucionais como as leis federais, estaduais, municipais e decretos que determinam a obrigatoriedade da mesma. Mediante isso, "O direito ao meio ambiente ecologicamente equilibrado passou a ser, a partir de 1988, um direito fundamental de todos os brasileiros e de todas as pessoas que estiverem no Brasil" (NALINI, 2003, p. 290).

Em consonância com as considerações de Nalini (2003), a Lei 9.795/99, de 27 de abril de 1999, institucionaliza a Política Nacional de Educação Ambiental, em que aborda a EA como componente essencial e permanente na educação nacional, além de entender que o processo educativo ambiental se dá por meio da construção de valores sociais, tanto individual como coletivo, com objetivo de abranger toda a sociedade. Essa lei visa também, contribuir para o desenvolvimento de uma consciência ambiental crítica, bem como estimular o enfrentamento de questões ambientais e sociais, a fim de promover a mudança cultural e social, de forma a atender a crise ambiental, num contexto ético e político, quando "Em 1999 é sancionada a Lei no 9.795/99 que institui a Política Nacional de Educação Ambiental, considerada uma vitória do movimento ambientalista" (PEDRINI; SÁNCHEZ, 2007, p. 31).

Portanto, é a partir de 1999 que a EA, no Brasil, passa a ser regida através de legislação específica, tendo como marco inaugural a lei que estabeleceu a Política Nacional de Educação Ambiental. Assim sendo, "A educação ambiental é uma das mais importantes exigências contemporâneas não só no Brasil, mas também no mundo" (REIGOTA, 2001, p. 58).

Desse modo, identifica-se que, no Brasil, a problemática ambiental permeia discussões em âmbito nacional e internacional, além de criação de leis e decretos com propósito de buscar possíveis soluções para os problemas ambientais atuais. 


\section{A práxis da educação ambiental na escola}

Na compreensão de Guimarães (2000), a EA visa estabelecer práticas sociais e políticas, numa perspectiva de desenvolver as relações entre a humanidade e a natureza. Logo, torna-se relevante a análise de sua efetivação na Escola Municipal Baixa da Fartura localizada no município de Vitória da Conquista/BA, conforme a figura 1.

Figura 1 - Cartograma de localização da Fazenda Amaralina

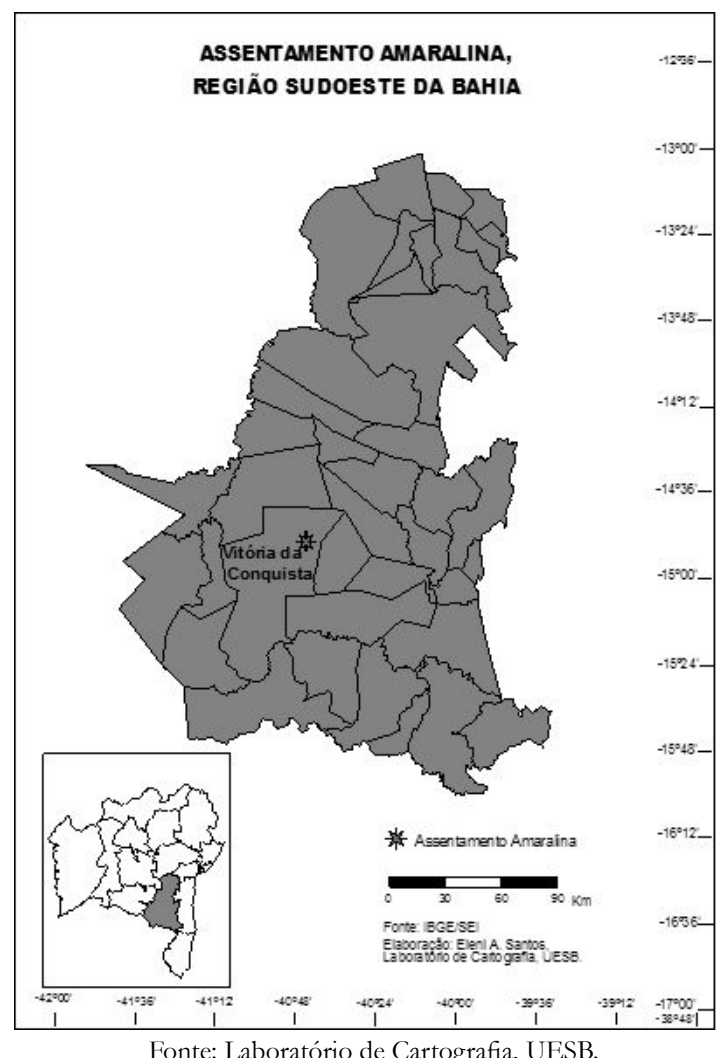

Fonte: Laboratório de Cartografia, UESB.

A instituição em estudo é mantida financeiramente pela Secretaria Municipal de Educação e Desportos (SMED) de Vitória da Conquista/BA. Porém, a pedagogia matriz está vinculada à Pedagogia 
do Movimento, baseada na luta social pela Reforma Agrária no Brasil, ou seja, a escola fundamenta-se em uma pedagogia definida como emancipatória, pois “[...] as escolas do assentamento teriam que ter um planejamento diferenciado, voltado para a especificidade da proposta pedagógica do MST" (PPP, 2006, p. 12).

A Escola não possui direção, por isso, as atividades ficam a cargo da coordenadora pedagógica, que dá suporte a mais 04 escolas, no mesmo Assentamento. A instituição possui duas salas de aula, sendo que as atividades pedagógicas são realizadas somente no turno matutino. $\mathrm{O}$ corpo docente composto por dois professores denominados aqui como: A e B. A professora A é graduanda em Licenciatura em Matemática e essa é a primeira experiência em sala de aula; a professora B é Bacharel em Agronomia e leciona há 02 anos em escola ligada ao MST.

Em relação à participação dos professores em cursos específicos na área ambiental, identificou-se que a professora A não participou de nenhum curso relacionado à EA ou meio ambiente. Enquanto que a professora B relatou ter participado de conferências sobre o meio ambiente, somente na graduação. Sobre a percepção dos professores em relação ao entendimento e a diferença entre EA e meio ambiente encontra-se no conjunto das respostas que essa educação está voltada para a preservação da natureza, além de declararem que, tanto a educação como a mídia e outros segmentos da sociedade, direcionam para a necessidade de preservar o meio ambiente.

A professora A define a EA como "[...] o meio ambiente em que os alunos vivem, relaciono ao desmatamento e desperdício do lixo, etc. O homem tem que cuidar do meio ambiente e isso é uma forma de educação". Já a professora B entende que "[...] a EA e meio ambiente são iguais e ambos estão totalmente ligados. Ultimamente, se discute a necessidade de preservar, mas o que se vê é pouca atitude dos seres humanos". Nessa perspectiva, constatou-se que as educadoras atribuem a EA somente a necessidade de preservar, e não se incluem como parte integrante do meio ambiente. 
As professoras consideram importante abordar as questões ambientais na escola como disciplina e não como tema transversal, justificando que o estudo ambiental como disciplina possui maior possibilidade da conscientização, por parte dos alunos, pois o tema será explorado de forma mais específica. Elas relataram que é importante trabalhar as questões ambientais na escola devido à necessidade de mostrar aos alunos a importância que a natureza representa para o ser humano.

Diante disso, solicitou-se dos docentes que relatassem como relacionam a EA com a práxis educacional e constatou-se que os professores valorizam a necessidade de preservar a natureza, além de trabalhar os conteúdos de higiene pessoal e do ambiente em que os alunos vivem, através de atividades realizadas como: leitura e produção de textos, cartazes, recortes de revistas que falam sobre a natureza.

A professora B diz produzir oficinas com garrafas pet, com o objetivo de traduzir a importância do reaproveitamento dessas garrafas, transformando-as em jogos, vassouras, jarros e outros objetos.

Os docentes colocaram ainda a existência de um calendário de datas comemorativas, que foi padronizado pela proposta educacional do MST no âmbito nacional, em que comemora o dia da árvore, do meio ambiente, a estação primavera e outras datas.

Refletindo sobre a necessidade dos discentes perceberem os problemas ambientais locais que ocorrem em torno da escola, os professores disseram que discutem sobre o lixo descartado pelos moradores que vivem próximo à instituição, e enfatizam que não há coleta de lixo no Assentamento. Destacaram também, a existência de lixo às margens do Rio Verruga, conforme mostra a figura 2, que passa no Assentamento Amaralina, e a existência de queimadas próximo à escola, o que acontece com frequência. 
Figura 2 - Rio Verruga que passa no Assentamento Amaralina

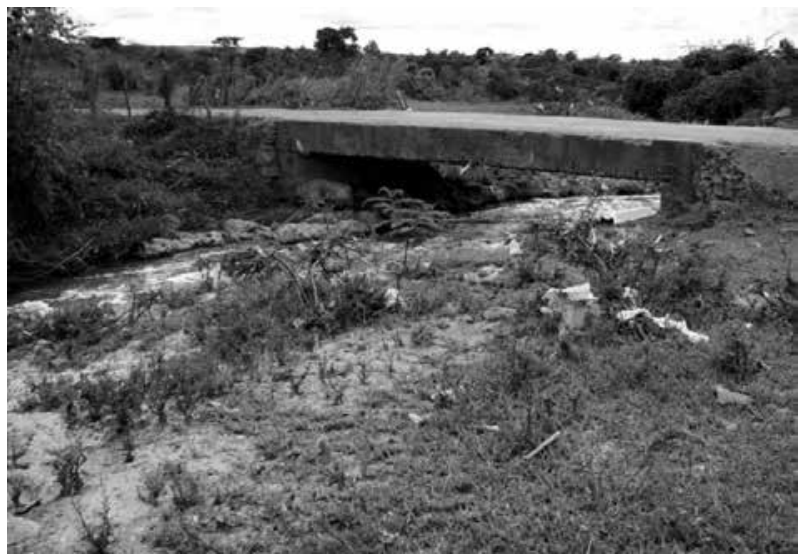

Fonte: Foto da autora, em pesquisa de campo, novembro de 2009.

Ao perguntar às educadoras sobre o destino do lixo produzido pela Escola e se abordam alguma reflexão, junto aos alunos, constatou- se que o lixo é queimado pela merendeira, em um buraco, atrás da escola, mas não relataram nenhum tipo de discussão com os alunos apontando o cuidado que devem ter com o descarte de lixo. Questionadas sobre a realização de atividades extraclasse relacionadas à questão ambiental e sua finalidade, responderam que promovem mutirão de limpeza no entorno da escola, mensalmente, e produzem a horta escolar com auxílio dos alunos, cujo objetivo é discutir, em classe, a importância de consumir alimentos como verduras e legumes. Segundo as entrevistadas, são cultivados na horta produtos como: cenoura, beterraba, pimentão, coentro, cebolinha e alface, que são utilizados no complemento da merenda escolar, conforme mostra a figura 3. 
Figura 3 - Horta da Escola Municipal Baixa da Fartura

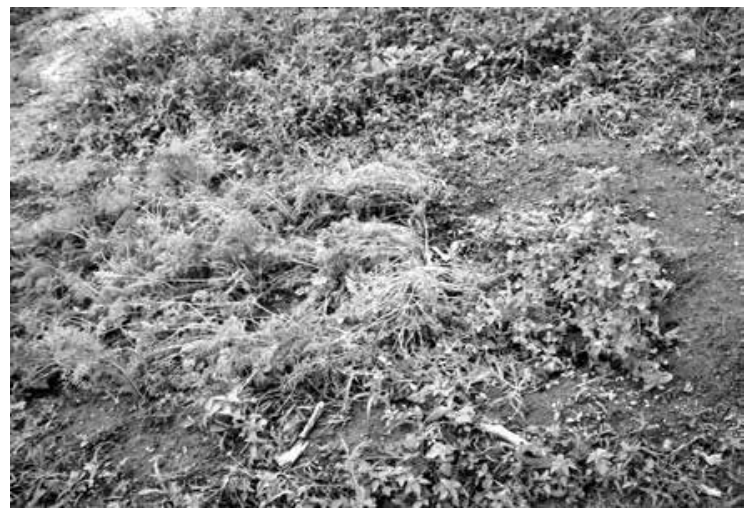

Fonte: Foto da autora, em pesquisa de campo, novembro de 2009.

Em relação às disciplinas que abordam os temas ambientais, ambas as professores destacaram a disciplina de Ciências, apontando a realização de aulas de campo utilizando as plantas que existem nas proximidades da escola, a qual possui árvores e plantas frutíferas, a saber: bananeira, laranjeira, limoeiro, pitangueira, mamoeiro, aceroleira, porém, não direcionam a forma como essas plantas são utilizadas como recurso didático.

Tanto a professora A quanto a B, destacaram que os alunos não sentem nenhuma dificuldade ao estudar os temas ambientais e elegem o lixo, as enchentes e as queimadas como temas referentes à problemática ambiental mais apontada por eles. Em relação às queimadas, os professores disseram que os educandos ficam indignados quando identificam áreas da fazenda que estão sendo queimadas.

A professora B relatou que "[...] os alunos ficam chocados quando assistem, nos telejornais, reportagens que mostram queimadas". No entanto, as docentes não apontam nenhuma atividade reflexiva relacionando as consequências provocadas pela prática das queimadas, e, ainda relataram não promoverem nenhuma discussão, com os alunos, em relação a poluição do Rio Verruga, que já chega ao Assentamento poluído.

Sobre as dificuldades para o desenvolvimento de atividades relacionadas à $\mathrm{EA}$, as discentes e a coordenadora pedagógica 
responderam que faltam recursos didáticos para trabalhar com as questões ambientais, justificando que a escola não disponibiliza material didático suficiente para desenvolver um bom trabalho e reconhecem que poderiam trabalhar melhor tanto as questões ambientais quanto os conteúdos convencionais se encontrassem à disposição materiais que favorecesse a dinamização do trabalho.

\section{Conclusão}

Deve-se pretender com a Educação Ambiental, em assentamentos, tal como o Assentamento Amaralina, o exercício da cidadania, com prioridade para a conscientização e busca de soluções para os problemas socioambientais locais, seguido de práticas muito além das formais, as quais são realizadas no Assentamento, sem nenhuma reflexão.

De tal modo, na perspectiva que a Educação Ambiental do Assentamento Amaralina não seja ingênua, é fundamental que os assentados sejam orientados, pelos dirigentes do MST, a refletirem as causas dos problemas socioambientais, no Assentamento.

Desse modo, sugere-se que os assentados reconheçam a importância da Educação Ambiental e possam auxiliar a produzir o diagnóstico dos problemas ambientais existentes na localidade em questão. Além disso, faz-se necessário buscar a Educação Ambiental no Assentamento para além de práticas individuais, ou seja, reestruturar as atividades de cunho ambientalista, na perspectiva da coletividade, para não seguir uma Educação Ambiental simplista.

No sentido de que a Educação Ambiental proporciona aos cidadãos, por meio de procedimentos pedagógicos permanentes, a orientação o ser humano sobre a condição mundial, nacional e local, referente à problemática ambiental, ousa-se apontar algumas sugestões para a viabilização da prática da Educação Ambiental, na Escola Municipal Baixa da Fartura.

Desse modo, considera-se que a instituição inicie ações contidas no Projeto Político Pedagógico, de forma participativa, já que aponta a proposta de desenvolver uma educação cooperativa e coletiva, em busca 
de realizar transformações sociais relacionando a discussão ambiental com temas que surgem da necessidade da própria comunidade escolar. Para isso, faz-se necessário optar por parcerias com as famílias resididas no assentamento, buscando envolvê-los na Educação Ambiental.

Propõe-se que a Escola realize, efetivamente, a propagação da Educação Ambiental como um processo de permanente aprendizado, a fim de valorizar as diversas formas de conhecimentos e desenvolver cidadãos conscientes dos problemas socioambientais da atualidade.

Para tanto, torna-se indispensável planejar e, sobretudo, executar atividades muito além das formais, às quais já são trabalhadas na instituição. Faz-se necessário, portanto, refletir no valor dessas atividades sem deixar de considerar que não são suficientes para contemplar à Educação Ambiental, de forma crítica e participativa.

Apesar de ter constatado, empiricamente, que o entendimento sobre a Educação Ambiental é confundida, pelos docentes da Escola Municipal Baixa da Fartura, com elementos da natureza, acredita-se que esse estudo possa contribuir com reflexões acerca da importância e possibilidade da difusão da Educação Ambiental, na instituição de ensino.

\section{Referências}

CRESPO, Samyra. Uma visão sobre a evolução da consciência ambiental no Brasil nos anos 1990. In: TRIGUEIRO, André. (Coord.). Meio ambiente no século 21: 21 especialistas falam da questão ambiental nas áreas de conhecimento. Rio de janeiro: Sextante, 2003.

FELDMAN, Fábio. A parte que nos cabe: consumo sustentável. In: TRIGUEIRO, André. (Coord.). Meio ambiente no século 21:21 especialistas falam da questão ambiental nas áreas de conhecimento. Rio de janeiro: Sextante, 2003.

GUIMARÃES, Mauro. Educação ambiental: no consenso um embate. São Paulo: Papirus, 2000. 